\title{
Surgical preferences of patients at risk of hip fractures: hemiarthroplasty versus total hip arthroplasty
}

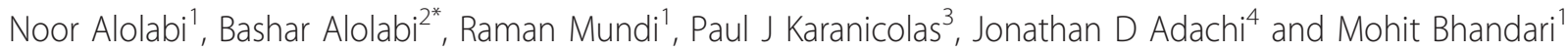

\begin{abstract}
Background: The optimal treatment of displaced femoral neck fractures in patients over 60 years is controversial. While much research has focused on the impact of total hip arthroplasty (THA) and hemiarthroplasty (HA) on surgical outcomes, little is known about patient preferences for either alternative. The purpose of this study was to elicit surgical preferences of patients at risk of sustaining hip fracture using a novel decision board.

Methods: We developed a decision board for the surgical management of displaced femoral neck fractures presenting risks and outcomes of HA and THA. The decision board was presented to 81 elderly patients at risk for developing femoral neck fractures identified from an osteoporosis clinic. The participants were faced with the scenario of sustaining a displaced femoral neck fracture and were asked to state their treatment option preference and rationale for operative procedure.
\end{abstract}

Results: Eighty-five percent (85\%) of participants were between the age of 60 and 80 years; $89 \%$ were female; $88 \%$ were Caucasian; and 49\% had some post-secondary education. Ninety-three percent (93\%; 95\% confidence interval [Cl], 87-99\%) of participants chose THA as their preferred operative choice. Participants identified several factors important to their decision, including the perception of greater walking distance (63\%), less residual pain (29\%), less reoperative risk (28\%) and lower mortality risk (20\%) with THA. Participants who preferred HA (7\%; 95\% Cl, 1 13\%) did so for perceived less invasiveness (50\%), lower dislocation risk (33\%), lower infection risk (33\%), and shorter operative time (17\%).

Conclusion: The overwhelming majority of patients preferred THA to HA for the treatment of a displaced femoral neck fracture when confronted with risks and outcomes of both procedures on a decision board.

\section{Background}

Hip fractures are suffered by 280, 000 Americans and 36, 000 Canadians annually [1]. As the population of those aged 65 years or older in North America will rise from 34.8 to 77.2 million by 2040 , the incidence of hip fractures is expected to exceed 500, 000 and 88, 000 in the United States and Canada respectively [1]. This increased incidence will correspondingly have an exhaustive economic toll, as health care costs surrounding hip fracture care will reach $\$ 9.8$ billion in the United States and $\$ 650$ million in Canada $[1,2]$.

\footnotetext{
* Correspondence: balolabi@gmail.com

${ }^{2}$ Department of Surgery, University of Western Ontario, 16-40 Fairfax Crt, London, ON, Canada N6G 3 Y3

Full list of author information is available at the end of the article
}

The optimal treatment of femoral neck fractures depends on a multitude of factors including the degree of fracture displacement and patient's age, risk profile, functional demands, cognitive function and physical fitness $[3,4]$. Three surgical options are available for such fractures: internal fixation, hemiarthroplasty (HA), and total hip arthroplasty (THA) [5,6]. Hemiarthroplasty is the treatment of choice in low-demand and cognitively impaired elderly patients [5]. However, the ideal management of displaced femoral neck fractures in relatively healthy, independent and lucid patients over the age of 60 years remains controversial [5,7]. Most orthopedic surgeons favour arthroplasty over internal fixation [5]. Recent studies have also demonstrated that arthroplasty produces superior functional results relative to internal fixation and is therefore preferable for this patient
C Biomed Central

(C) 2011 Alolabi et al; licensee BioMed Central Ltd. This is an Open Access article distributed under the terms of the Creative Commons Attribution License (http://creativecommons.org/licenses/by/2.0), which permits unrestricted use, distribution, and reproduction in any medium, provided the original work is properly cited. 
population [8-10]. However, debate continues among surgeons as to whether HA or THA is optimal, with most surgeons favouring HA $[5,11]$. Proponents of HA quote the advantages of a shorter and simpler surgical procedure, reduced risk of dislocation and the decreased component costs. On the other hand, advocates of THA criticize HA since it results in rapid wear of the acetabular articular cartilage and emphasize that THA is associated with improved functional outcomes, lower postoperative pain scores and potential decrease in reoperation rates [7,9,10,12-16].

When varying treatment options exist favouring different outcomes and risks, which may be valued differently by patients and physicians, it becomes critical to incorporate and rely on patients' preferences in recommending treatment options [17]. Moreover, information regarding the different surgical options and their outcomes should be delivered to patients in a thorough, consistent and unbiased manner [18]. Decision aids can be invaluable resources to aid surgeons in this communication task. Decision aids are "tools designed to help people participate in decision making about health care options" [19]. They provide clear information on the treatment options as well as their risks and benefits and thus assist patients clarify and communicate the personal value they associate with different features of the options [19].

Despite the controversy surrounding hip fracture care, the orthopaedic literature is void of studies eliciting patient's preferences and detailing the effectiveness of decision aids to inform patients of hip fracture management [20]. The purpose of this study was to utilize a decision board to elicit surgical preferences for treatment of displaced femoral neck fractures from patients at risk for sustaining this fracture.

\section{Methods}

\section{Decision aid development}

We developed an electronic decision board following accepted decision board development methods [21-25]. The decision tool fulfilled the CREDIBLE criteria for assessing decision tool quality [26].

The contents of the decision board were abstracted from a systematic review conducted to identify all randomized controlled trials comparing HA and THA for the treatment of displaced femoral neck fractures in patients over the age of 60 years. We searched articles using MEDLINE and EMBASE from 1966 to January 2007. No language restrictions were applied. The bibliographies of all retrieved publications were reviewed for additional relevant articles. The article titles and abstracts were then assessed to ensure that the study was a randomized trial involving the treatment of displaced femoral neck fractures with HA or THA. The data abstracted from the eligible studies consisted of interventions, duration of surgery, functional outcomes and rates of complications (infections, dislocations, medical complications, reoperations and mortality).

Five randomized controlled trials met the inclusion criteria $[9,10,16,27,28]$. The paper by Ravikumar [9] represents a 13-year follow-up of the Skinner trial [10] and therefore it was not used for our data abstraction. The results of the remaining 4 studies were pooled across studies using estimates from individual trials weighted based on sample size to produce the data presented in the electronic decision aid (Table 1).

The information included in the electronic decision board (Figure 1) was based on a previously developed orthopedic decision board addressing treatment options for displaced femoral neck fractures [29]. This information included a background about femoral neck fractures, a description of the two treatment options [30] (HA and THA) and their respective outcomes and risks. We used the terms "metallic ball" and "metallic ball and socket" to avoid bias by introducing the words "hemi/ partial" and "total". We presented the outcomes as probabilities using the phrase, "Out of 100 patients who will have this procedure, a certain number will develop the complication indicated."

Decision boards have been extensively tested in multiple medical fields including orthopedic surgery, and shown to be valid, reliable and easily administered tools $[21,31,32]$. We were confident in the reliability of this decision board given our previous evaluation of a similar decision board on femoral neck fractures [29].

\section{Participants}

Approval was obtained from the local research ethics board for the study. Participants were recruited from an osteoporosis clinic. Participants were all independent, competent and over the age of 60 years. This population was selected as the study subjects because older patients with osteoporosis would represent a high-risk group to suffer femoral neck fractures [14,33-38].

Participants were excluded if they were incompetent cognitively or if they had a previous hip fracture or replacement, since their choice could be biased towards or against the treatment option they previously received. Patients arriving at the osteoporosis clinic were screened for eligibility; if they met the criteria, then they were asked to participate and included in the study if they provided consent.

\section{Decision board administration}

The decision board was administered to participants by two of the authors (N.A. and R.M.). After the board was developed, a guideline outlining what and how information would be presented was established between the 
Table 1 Derivation of the pooled data used in the decision board based on the outcomes from the included clinical trials

\begin{tabular}{|c|c|c|}
\hline Outcomes & THA & HA \\
\hline \multicolumn{3}{|c|}{ Operative Time } \\
\hline Keating & 80 & 59 \\
\hline Dorr & - & - \\
\hline Baker & 93 & 78 \\
\hline Skinner & - & - \\
\hline Pooled Data & $87 \mathrm{~min}$ & $69 \mathrm{~min}$ \\
\hline \multicolumn{3}{|c|}{ Post-operative Walking Distance } \\
\hline Keating & - & - \\
\hline Dorr & - & - \\
\hline Baker & $3.6 \mathrm{Km}$ & $1.9 \mathrm{Km}$ \\
\hline Skinner & - & - \\
\hline Pooled Data & $3.6 \mathrm{Km}$ & $1.9 \mathrm{Km}$ \\
\hline \multicolumn{3}{|l|}{ Residual Pain } \\
\hline Keating & $29 / 61$ & $30 / 60$ \\
\hline Dorr & - & - \\
\hline Baker & - & - \\
\hline Skinner & $0 / 62$ & $20 / 73$ \\
\hline Pooled Data & 29/123 (24\%) & $50 / 133(38 \%)$ \\
\hline \multicolumn{3}{|c|}{ Failure to Regain Mobility } \\
\hline Keating & - & - \\
\hline Dorr & $7 / 39$ & $15 / 50$ \\
\hline Baker & - & - \\
\hline Skinner & $13 / 62$ & $11 / 73$ \\
\hline Pooled Data & 20/101 (20\%) & $26 / 123(21 \%)$ \\
\hline \multicolumn{3}{|l|}{ Dislocation } \\
\hline Keating & $3 / 69$ & $2 / 69$ \\
\hline Dorr & $7 / 39$ & $2 / 50$ \\
\hline Baker & $3 / 40$ & $0 / 41$ \\
\hline Skinner & $10 / 80$ & $11 / 100$ \\
\hline Pooled Data & $23 / 228(10 \%)$ & $15 / 260(6 \%)$ \\
\hline \multicolumn{3}{|c|}{ Medical Complications } \\
\hline Keating & $14 / 69$ & $12 / 69$ \\
\hline Dorr & - & - \\
\hline Baker & $1 / 40$ & $3 / 41$ \\
\hline Skinner & - & - \\
\hline Pooled Data & 15/109 (14\%) & $15 / 110(14 \%)$ \\
\hline \multicolumn{3}{|c|}{ Superficial Wound Infection } \\
\hline Keating & $2 / 69$ & $2 / 69$ \\
\hline Dorr & $0 / 39$ & $0 / 50$ \\
\hline Baker & $2 / 40$ & $1 / 41$ \\
\hline Skinner & - & - \\
\hline Pooled Data & $4 / 148(3 \%)$ & $3 / 160(2 \%)$ \\
\hline \multicolumn{3}{|c|}{ Deep Wound Infection } \\
\hline Keating & $1 / 69$ & $1 / 69$ \\
\hline Dorr & $0 / 39$ & $0 / 50$ \\
\hline
\end{tabular}

Table 1 Derivation of the pooled data used in the decision board based on the outcomes from the included clinical trials (Continued)

\begin{tabular}{|c|c|c|}
\hline Baker & $1 / 40$ & $0 / 41$ \\
\hline Skinner & $1 / 80$ & $0 / 100$ \\
\hline Pooled Data & $3 / 228(1 \%)$ & $1 / 260(0 \%)$ \\
\hline \multicolumn{3}{|c|}{ Reoperation within 1 year } \\
\hline Keating & $6 / 69$ & $5 / 69$ \\
\hline Dorr & $9 / 39$ & $6 / 50$ \\
\hline Baker & $1 / 40$ & $6 / 41$ \\
\hline Skinner & $13 / 80$ & $24 / 100$ \\
\hline Pooled Data & $29 / 228(13 \%)$ & $41 / 260(16 \%)$ \\
\hline \multicolumn{3}{|c|}{ 3-4 month Mortality } \\
\hline Keating & $2 / 69$ & $5 / 69$ \\
\hline Dorr & - & - \\
\hline Baker & - & - \\
\hline Skinner & $8 / 80$ & $15 / 100$ \\
\hline Pooled Data & 10/149 (7\%) & $20 / 169(12 \%)$ \\
\hline \multicolumn{3}{|c|}{1 year Mortality } \\
\hline Keating & 4 & 6 \\
\hline Dorr & - & - \\
\hline Baker & - & - \\
\hline Skinner & 18 & 27 \\
\hline Pooled Data & $22 / 149(15 \%)$ & $33 / 169(20 \%)$ \\
\hline
\end{tabular}

two interviewers. In addition, the interviewers administered the decision board to each other to ensure consistency in the way the interview was conducted.

Participants were presented with the following hypothetical scenario: "While walking, you slip on ice and fall down. You are taken to the nearest hospital and after careful physical and radiographic examination, you are found to have a femoral neck fracture (a fracture of the long thigh bone at the hip level). The orthopedic surgeon tells you that there are two treatment options for this type of fracture." The decision board was then presented to the participants, who read each part of the decision board independently. Questions were encouraged at any time during the interview to clarify vague information or address any concerns. All questions were answered ensuring that the interviewers elicited no bias. Participants' stated their preferences for treatment and the strength of their choice using a 7-point adjectival scale (1-I definitely prefer metallic ball and socket; 4-I am indifferent; 7-I definitely prefer metallic ball). They were then asked for the primary reasons of their treatment option choice.

\section{Demographic and satisfaction questionnaire}

At the end of the interview, the participants completed a questionnaire on socio-demographic variables (gender, 


\section{Decision Board}

\section{Replacing the Fracture with a Metallic Ball \& Socket}

- The anesthesiologist will put you to sleep or will freeze your hip by a needle into your back

- The surgeon will make a cut in the skin at the side of your thigh that measures 15 centimetres.

- The surgeon will remove the broken ball of your hip

- The surgeon will put a metallic stem into your thigh bone (femur) and a metallic socket into your pelvis. The surgeon will then attach a metallic ball to the stem as shown in the picture.

- The surgeon will close the skin with staples.

\section{Categories of Treatment Outcomes}

- Average duration of the operation

- Average walking distance after operation (3.6 km pre-op)

- Patients who will have residual pain after 1 year of the operation

- Patients who will fail to regain mobility after 1 year of the operation

- Patients who will have a dislocation of the hip joint

- Patients who will have a medical complication

- Patients who will have a superficial wound infection requiring antibiotics

- Patients who will have a deep wound infection requiring another operation

- Patients who will have another operation within 1 year of the operation

- Patients who will die within 3-4 months of the operation

- Patients who will die within 1 year of the operation

\section{Preamble}

- Fracture of the neck of the femur is a fracture or break below the ball of the hip joint

- 4 out of 1000 Canadians older than 60 years old will have this fracture

- There are two options to treat this fracture. Each has benefits and risks.

- You will be shown the treatment options and their possible outcomes.

- You will be asked about your preference between the two options.

\section{Replacing the Fracture with a Metallic Ball}

- The anesthesiologist will put you to sleep or will freeze your hip by a needle into your back

- The surgeon will make a cut in the skin at the side of your thigh that measures 15 centimetres.

- The surgeon will remove the broken ball of your hip.

- The surgeon will put a metallic stem into your thigh bone (femur). The surgeon will then attach a metallic ball to the stem as shown in the picture.

- The surgeon will close the skin with staples.

Out of 100 patients who will have Metallic Ball / Ball \& Socket:

\begin{tabular}{|l|c|c|}
\hline \multicolumn{1}{|c|}{ Treatment Outcomes } & Metallic Ball & $\begin{array}{c}\text { Metallic Ball \& } \\
\text { Socket }\end{array}$ \\
\hline Duration of the operation & $69 \mathrm{~min}$. & $87 \mathrm{~min}$. \\
\hline Walking distance post-op (3.6 km pre-op) & $1.6 \mathrm{~km}$ & $3.6 \mathrm{~km}$ \\
\hline Residual pain after 1 year & 38 & 24 \\
\hline Failure to regain mobility & 21 & 20 \\
\hline Dislocation of the hip joint & 6 & 10 \\
\hline Medical complication & 14 & 14 \\
\hline Superficial wound infection - antibiotics & 2 & 3 \\
\hline Deep wound infection - another operation & 0 & 1 \\
\hline Another operation within 1 year & 16 & 13 \\
\hline Mortality within 3-4 months & 12 & 7 \\
\hline Mortality within 1 year & 20 & 15 \\
\hline
\end{tabular}

Figure 1 An Illustration of the decision board.

age, race, educational level, occupation, and income), previous history of fractures, and an evaluation for the acceptability and satisfaction of using the decision board as a tool to inform patients about treatment options. Acceptability of the decision board was assessed by asking questions regarding how well they understood the board, its usefulness in helping them make a decision, and whether they would recommend it for others. Satisfaction was assessed with respect to the amount of information provided, the use of the decision board as a 
method to present material and its use of the as a decision-making tool.

\section{Data analysis}

For each study, we calculated the means differences for continuous outcomes. When possible, we pooled the estimates from individual trials based on sample size. Group data were summarized in terms of frequency and percentage (with 95\% confidence intervals). With approximately $70 \%$ of participants choosing one surgical option, we determined that a sample size of 80 would be needed for a $95 \%$ confidence interval $+/-10 \%$.

\section{Results}

Between May 2008 and May 2009, we screened participants in the osteoporosis clinic for eligibility. Eight-four participants met eligibility criteria and were recruited. Three participants were omitted from the study postinterview; one had Alzheimer's disease and two did not understand English well. Data was therefore collected and analyzed for 81 participants.

Eighty-five percent (85\%) of participants were between the age of 60 and 80 years; $89 \%$ were female; $88 \%$ were Caucasian; and $49 \%$ had some post-secondary education (Table 2). By far, the majority of participants had a documented diagnosis of osteoporosis. The remainder minority had predisposing factors putting them at a high risk for developing osteoporosis.

Of 81 participants, 75 (93\%; 95\% confidence intervals [CI], 87-99) chose THA as their preferred treatment option. The main factors contributing to this choice included the perception of ability to walk a greater distance (63\%; CI, 52-74), less residual pain (29\%; CI, 19 $39)$, lower reoperative risk (28\%; CI, 18-28), and lower mortality (20\%; CI, 11-29) (Figure 2). Participants who chose HA (7\%; CI, 1-13) as their preferred treatment choice cited less invasiveness (50\%; CI, 39-61), less dislocation (33\%; CI, 23-43), less infection (33\%; CI, 23-43), and shorter operative time (17\%; CI, 9-25) (Figure 3). The majority of those who chose THA were quite comfortable with their preference as indicated by their strength of choice, whereas the majority of those who chose HA were closer to being indifferent (Figure 4).

All participants completed the acceptability and satisfaction questionnaire. Ninety-eight percent (98\%; CI, 95101) of participants stated that the decision board was easy to understand, $96 \%(\mathrm{CI}, 92-100)$ reported that it helped them make a decision, and 96\% (CI, 92-100) indicated that they would recommend the use of the decision board to others. Furthermore, 100\%, 97\% (CI, 93-101) and 97\% (CI, 93-101) of participants were satisfied with the decision board as a method for presenting information, the amount of information presented, and the use of the decision board as a decision-making tool respectively (Figure 5 ).

\section{Discussion}

This decision board analysis demonstrates that the overwhelming majority of participants preferred total hip arthroplasty to hemiarthroplasty for the treatment of displaced femoral neck fractures in patients over 60 years. The main contributing factors for this preference

Table 2 Participants' Demographics

\begin{tabular}{|c|c|c|c|c|}
\hline Demographic Category & & THA $(n=75)$ & $H A(n=6)$ & Total $(n=81)$ \\
\hline \multirow[t]{2}{*}{ Gender } & Male & $6(8 \%)$ & $3(50 \%)$ & $9(11 \%)$ \\
\hline & Female & $69(92 \%)$ & $3(50 \%)$ & $72(89 \%)$ \\
\hline \multirow[t]{4}{*}{ Age } & $60-70$ y.o & $38(51 \%)$ & $1(17 \%)$ & $39(48 \%)$ \\
\hline & $70-80$ у.о & $27(36 \%)$ & $3(50 \%)$ & $30(37 \%)$ \\
\hline & $80-90$ у.о & $9(12 \%)$ & $2(33 \%)$ & $11(14 \%)$ \\
\hline & $>90$ y.o & $1(1 \%)$ & $0(0 \%)$ & $1(1 \%)$ \\
\hline \multirow[t]{5}{*}{ Race } & White or Caucasian & 67 (89\%) & $4(67 \%)$ & $71(88 \%)$ \\
\hline & $\overline{\text { Asian }}$ & $1(1 \%)$ & $0(0 \%)$ & $1(1 \%)$ \\
\hline & Black & $2(3 \%)$ & $0(0 \%)$ & $2(2 \%)$ \\
\hline & South Asian & $2(3 \%)$ & $1(17 \%)$ & $3(4 \%)$ \\
\hline & Other & $3(4 \%)$ & $1(17 \%)$ & $4(5 \%)$ \\
\hline \multirow[t]{3}{*}{ Education Level } & High School & $28(37 \%)$ & $2(33 \%)$ & $30(37 \%)$ \\
\hline & Post-Secondary & $38(51 \%)$ & $2(33 \%)$ & 40 (49\%) \\
\hline & Other & $9(12 \%)$ & $2(33 \%)$ & $11(14 \%)$ \\
\hline \multirow[t]{3}{*}{ Income $(n=55$ for THA, 5 for HA and 60 for Total) } & $\$ 0-\$ 40,000$ & $31(56 \%)$ & $5(100 \%)$ & $36(60 \%)$ \\
\hline & $\$ 40,000-\$ 80,000$ & $24(44 \%)$ & $0(0 \%)$ & $24(40 \%)$ \\
\hline & $>\$ 80,000$ & $0(0 \%)$ & $0(0 \%)$ & $0(0 \%)$ \\
\hline
\end{tabular}




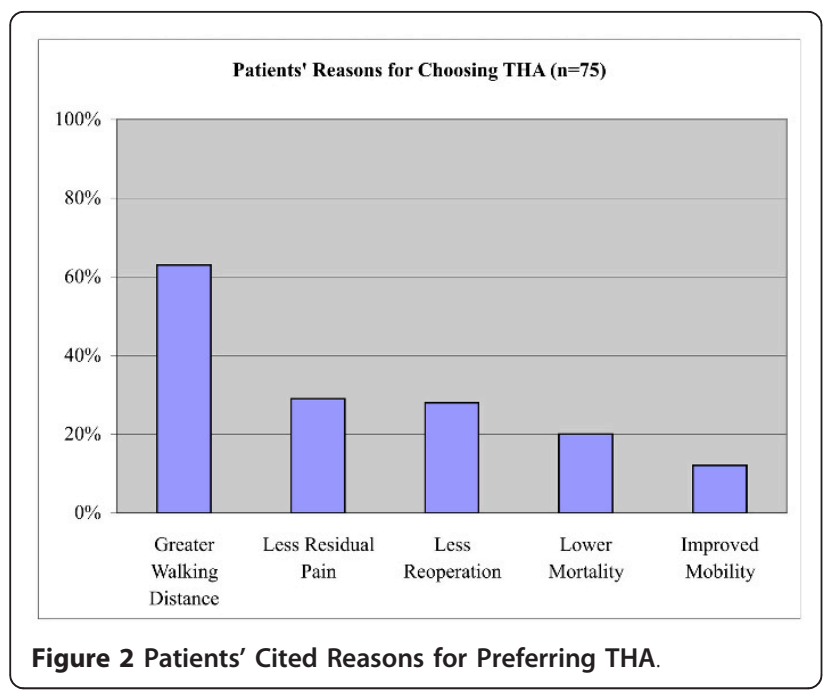

were greater post-operative walking distance, less residual pain, and reduced risk of reoperation. Interestingly, most orthopedic surgeons have the opposite preference; an international survey by Bhandari et al. as well as a survey administered to the American Association of Hip and Knee Surgeons both illustrated that $80-85 \%$ of surgeons favor hemiarthroplasty over total hip arthroplasty for the treatment of displaced femoral neck fractures in patients over 60 years $[5,11]$.

Our findings demonstrate a substantial discrepancy between patient and surgeon preferences for the treatment of displaced femoral neck fractures. Other studies have demonstrated that there is a gap between patient and physician preferences $[39,40]$. For example, compared to physicians, patients are willing to accept a much higher bleeding risk for an associated reduction in risk of stroke [39], and cancer patients are willing to

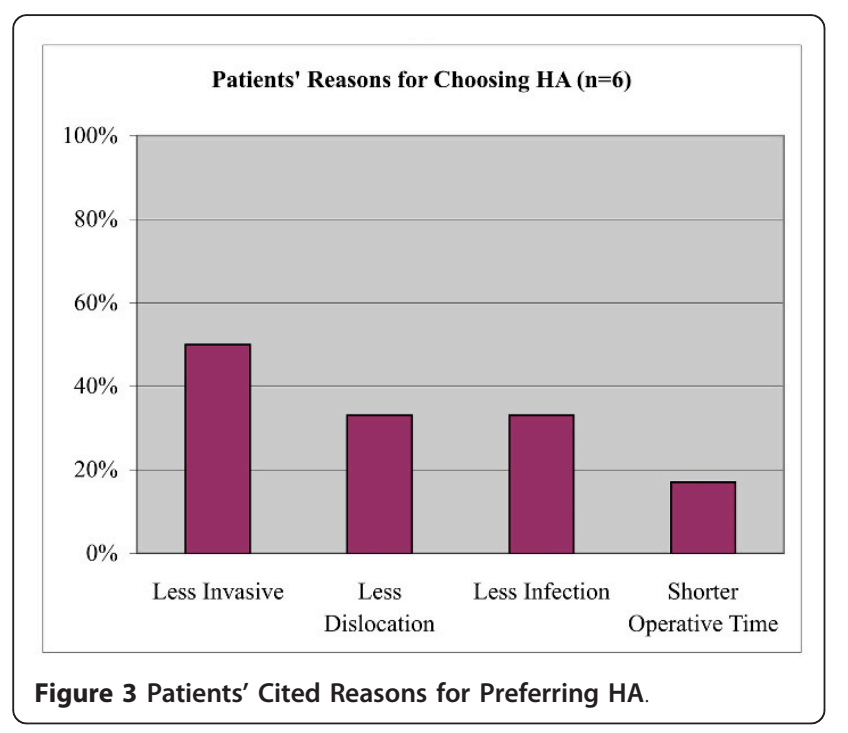

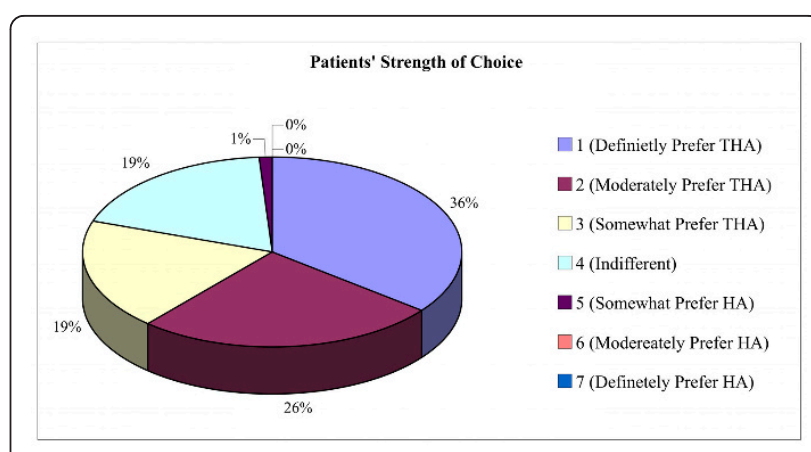

Figure 4 Patients' Strength of Choice.

accept treatment with severe side effects for a much smaller chance of improvement [40]. It is therefore important for clinicians not to assume their patients' preference and to ensure that their patients are well informed about treatment options in an unbiased manner.

Involving patients in the decision-making process is the focus of patient-centered care. Studies have revealed that involving patients in their care changes patient behavior and increases compliance with treatment $[41,42]$. Decision aids can be invaluable resources, assisting physicians to relay unbiased information to patients during this shared decision-making process $[18,20]$. A systematic review of 55 randomized controlled trials evaluating the efficacy of decision aids compared to no aid, usual care, or an alternative intervention, illustrated that patients who used a decision aid were more satisfied and had greater knowledge and less decisional conflict relative to patients in the other groups [26]. In our study, the majority of patients found the decision board easy to understand, enabled them to make a decision and were satisfied with it as a method to present information and as a decision making tool.

At the time of the onset of our study, only the trials included in our study were published. However, there have been a number of trials and reviews published since then, most favoring THA over HA [8,12-14,43,44] and others showing no advantage of THA over HA and thus favoring HA [45]. Although we acknowledge that these new studies may affect the results of our study, however, most studies still demonstrate similar trends to our decision board. Since the controversy regarding THA and HA for the treatment of displaced femoral neck fractures still exists, eliciting patients' preferences is important.

The treatment choices presented to the participants in our study included HA and THA. A non-operative approach was not included since it is restricted to a very narrow patient group with significant medical conditions preventing them from operative treatment. Similarly, 


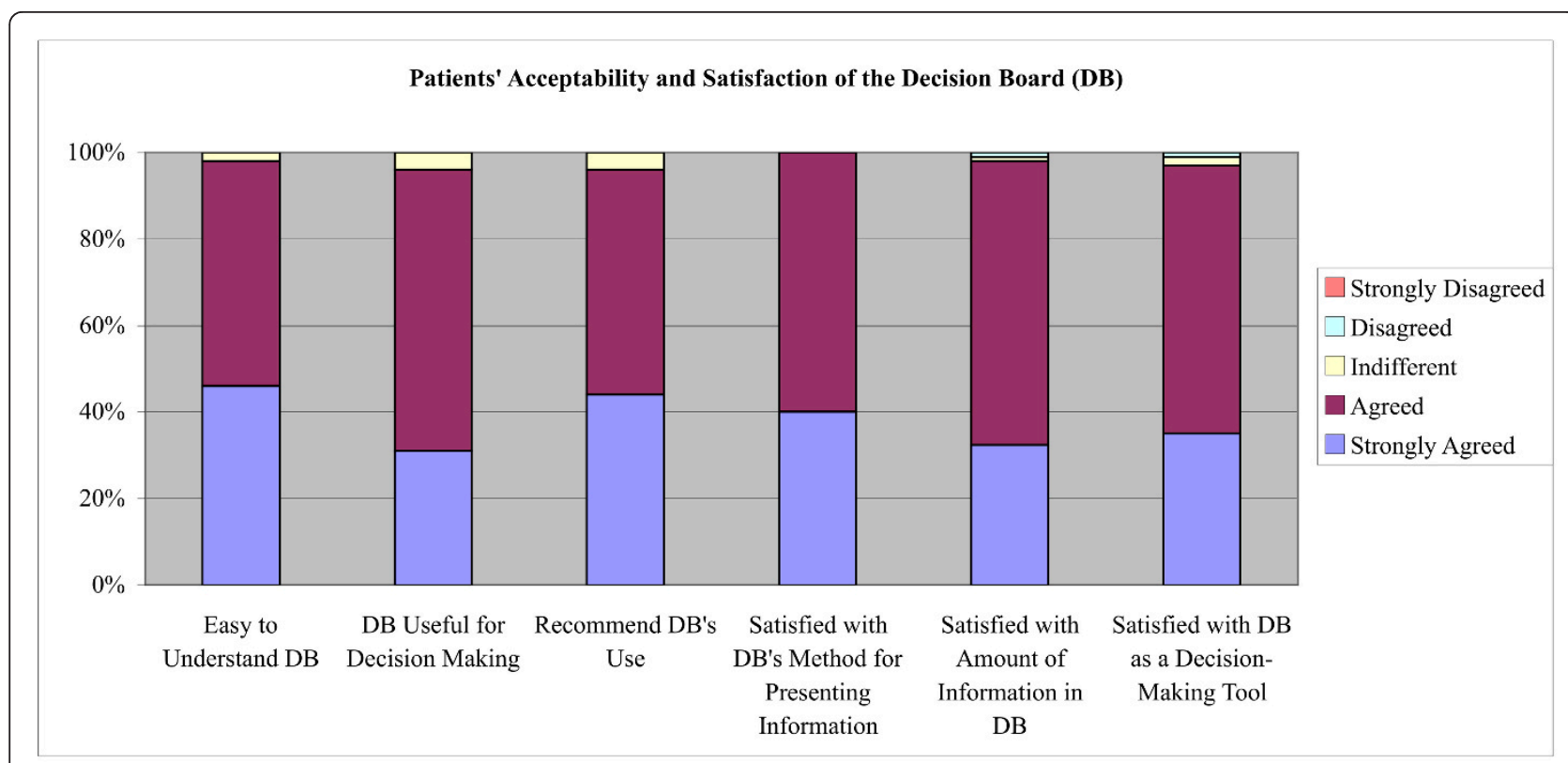

Figure 5 Patients' Acceptability and Satisfaction with the Decision Board.

internal fixation was not considered because we have previously performed a similar study eliciting treatment preferences between internal fixation and hemiarthroplasty [29].

Our study has several strengths. We followed rigorous, well-defined methodology to develop the decision aid. We used one-on-one interviews to ensure that all participants understood the questions being asked and provided their true preferences. All participants were above 60 years and $85 \%$ of them were between the ages of 60 and 80-the main controversial age group for treatment of these fractures. Furthermore, the patients were recruited from an osteoporosis clinic and had no previous history of hip fracture, which made them a highrisk population for intracapsular hip fractures yet avoided biases such as chronic pain secondary to osteoarthritis or a prior hip replacement with HA or THA.

The main limitation of this study is the study population. Ideally we would have involved real patients with displaced intracapsular hip fractures at the point of decision-making. However, this task is a challenging one since most surgeons often have strong preferences about the appropriate treatment modality of individual patients [13]. Also, at our institution, and many other institutions, THA is performed only by specially trained arthroplasty surgeons, who represent a small portion of surgeons treating acute femoral neck fractures. Hence, we could not administer the decision board and elicit preferences in actual hip fracture patients since it would not be possible or practical to offer all patients THA if they chose it as their preferred treatment option. However, the study population we studied was perhaps the closest to real patients. The typical patient presenting with a femoral neck fracture is a woman over 60 years with osteoporosis and other comorbidities [14,33-38]. Osteoporosis and prior fragility fractures are the most significant risk factors for hip fracture. Many other risk factors including age, female sex, family history of fractures and body mass are indirect measures or risk factors of osteoporosis [34]. We chose independent and competent patients over the age of 60 years who were at an osteoporosis clinic either for treatment of a documented diagnosis of osteoporosis or a condition predisposing them to develop osteoporosis. Also, most of our patients were females. Therefore, we believe that this patient population is highly representative of actual independent and relatively active patients with an intracapsular hip fracture. Another limitation is the fact that newer trials comparing THA and HA are not included in the decision board data but, as mentioned, these studies were not published at the time of onset of this study.

\section{Conclusion}

The overwhelming majority of patients prefer THA to HA for the treatment of displaced femoral neck fractures, despite the current trend of surgeons to favor HA over THA. Surgeons should discuss the advantages and disadvantages of each approach with individual patients and involve them in a shared decision-making process. Decision aids may be helpful to surgeons in 
this process, as well as other areas of surgical management.

\section{Acknowledgements}

There are no acknowledgements and no funding was obtained for this project.

\section{Author details}

${ }^{1}$ Division of Orthopaedic Surgery, McMaster University, Hamilton, Canada. ${ }^{2}$ Department of Surgery, University of Western Ontario, 16-40 Fairfax Crt, London, ON, Canada N6G 3Y3. ${ }^{3}$ Memorial Sloan-Kettering Cancer Center, 1275 York Ave., New York, NY, USA 10065. ${ }^{4}$ Department of Medicine, McMaster University, Hamilton, Canada.

\section{Authors' contributions}

NA interviewed the majority of the patients, acquired the data and contributed in writing the manuscript. BA designed the study and decision board, obtained REB approval and assisted with data analysis and manuscript preparation. RM interviewed the remainder of the patients, acquired the data and contributed in writing the manuscript. PJK was involved in the study design, assisted with data analysis and helped with manuscript preparation. JDA was involved in patient recruitment and interviews and assisted with manuscript preparation. MB is the study supervisor; he assisted with study design and manuscript preparation. All authors read and approved the final manuscript.

\section{Competing interests}

The authors declare that they have no competing interests.

Received: 6 August 2011 Accepted: 23 December 2011 Published: 23 December 2011

\section{References}

1. Schemitsch $E$, Bhandari M: Femoral neck fractures: controversies and evidence. J Orthop Trauma 2009, 23(6):385.

2. Zlowodzki M, Tornetta P, Haidukewych G, Hanson BP, Petrisor B, Swiontkowski MF, Schemitsch EH, Giannoudis PV, Bhandari M: Femoral neck fractures: evidence versus beliefs about predictors of outcome. Orthopedics 2009, 32(4)[http://orthosupersite.com/view.asp?rlD=38062].

3. Masson $\mathrm{M}$, Parker $\mathrm{MJ}$, Fleischer S: Internal fixation versus arthroplasty for intracapsular proximal femoral fractures in adults. Cochrane Database Syst Rev 2003, CD001708, (2)(2).

4. Tidermark J: Quality of life and femoral neck fractures. Acta Orthop Scand Suppl 2003, 74(309):1-42.

5. Bhandari M, Devereaux PJ, Tornetta P, Swiontkowski MF, Berry DJ, Haidukewych G, Schemitsch EH, Hanson BP, Koval K, Dirschl D, Leece P, Keel M, Petrisor B, Heetveld M, Guyatt GH: Operative management of displaced femoral neck fractures in elderly patients: an international survey. J Bone Joint Surg Am 2005, 87(9):2122-2130.

6. Heetveld MJ, Rogmark C, Frihagen F, Keating J: Internal fixation versus arthroplasty for displaced femoral neck fractures: What is the evidence? J Orthop Trauma 2009, 23(6):395-402.

7. Schmidt AH, Leighton R, Parvizi J, Sems A, Berry DJ: Optimal arthroplasty for femoral neck fractures: Is total hip arthroplasty the answer? J Orthop Trauma 2009, 23(6):428-433.

8. Mouzopoulos $\mathrm{G}$, Stamatakos M, Arabatzi H, Vasiliadis G, Batanis $\mathrm{G}$, Tsembeli A, Tzurbakis M, Safioleas M: The four-year functional result after a displaced subcapital hip fracture treated with three different surgical options. Int Orthop 2008, 32(3):367-373.

9. Ravikumar KJ, Marsh G: Internal fixation versus hemiarthroplasty versus total hip arthroplasty for displaced subcapital fractures of femur-13 year results of a prospective randomised study. Injury 2000, 31(10):793-797.

10. Skinner P, Riley D, Ellery J, Beaumont A, Coumine R, Shafighian B: Displaced subcapital fractures of the femur: a prospective randomized comparison of internal fixation, hemiarthroplasty and total hip replacement. Injury 1989, 20(5):291-293.

11. Iorio R, Schwartz B, Macaulay W, Teeney SM, Healy WL, York S: Surgical treatment of displaced femoral neck fractures in the elderly: a survey of the American Association of Hip and Knee Surgeons. J Arthroplasty 2006, 21(8):1124-1133.

12. Macaulay W, Nellans KW, Garvin KL, lorio R, Healy WL, Rosenwasser MP, other members of the DFACTO Consortium: Prospective randomized clinical trial comparing hemiarthroplasty to total hip arthroplasty in the treatment of displaced femoral neck fractures: Winner of the Dorr award. J Arthroplasty 2008, 23(6 Suppl 1):2-8.

13. Blomfeldt R, Tornkvist $H$, Eriksson $K$, Soderqvist A, Ponzer S, Tidermark J: A randomised controlled trial comparing bipolar hemiarthroplasty with total hip replacement for displaced intracapsular fractures of the femoral neck in elderly patients. J Bone Joint Surg Br 2007, 89(2):160-165.

14. Hopley C, Stengel D, Ekkernkamp A, Wich M: Primary total hip arthroplasty versus hemiarthroplasty for displaced intracapsular hip fractures in older patients: systematic review. BMJ 2010, 340:c2332.

15. Rodriguez-Merchan EC: Displaced intracapsular hip fractures: hemiarthroplasty or total arthroplasty? Clin Orthop Relat Res 2002, 399(399):72-77.

16. Keating JF, Grant A, Masson M, Scott NW, Forbes JF: Randomized comparison of reduction and fixation, bipolar hemiarthroplasty, and total hip arthroplasty. Treatment of displaced intracapsular hip fractures in healthy older patients. J Bone Joint Surg Am 2006, 88(2):249-260.

17. Guyatt GH, Haynes RB, Jaeschke R, Cook D, Greenhalgh T, Meade M, Green L, Naylor CD, Wilson M, McAlister F, Richardson WS: Introduction: the philosophy of evidence-based medicine. In Users' Guides to the Medical Literature: A Manual of Evidence-Based Clinical Practice. Edited by: Guyatt GH, Rennie D. Chicago: American Medical Association; 2002:3-12.

18. Bryant D, Bednarski E, Gafni A: Incorporating patient preferences into orthopaedic practice: should the orthopaedic encounter change? Injury 2006, 37(4):328-334.

19. International patient decision aid standards (IPDAS) collaboration. [http://ipdas.ohri.ca/what.html], Accessed August 3, 2010.

20. Adam JA, Khaw FM, Thomson RG, Gregg PJ, Llewellyn-Thomas HA: Patient decision aids in joint replacement surgery: a literature review and an opinion survey of consultant orthopaedic surgeons. Ann R Coll Surg Engl 2008, 90(3):198-207.

21. Levine MN, Gafni A, Markham B, MacFarlane D: A bedside decision instrument to elicit a patient's preference concerning adjuvant chemotherapy for breast cancer. Ann Intern Med 1992, 117(1):53-58.

22. Whelan T, Gafni A, Charles C, Levine M: Lessons learned from the decision board: A unique and evolving decision aid. Health Expect 2000, 3(1):69-76.

23. Whelan T, Levine M, Gafni A, Sanders K, Willan A, Mirsky D, Schnider D, McCready D, Reid S, Kobylecky A, Reed K: Mastectomy or lumpectomy? Helping women make informed choices. J Clin Oncol 1999, 17(6):1727-1735.

24. Whelan T, Levine M, Willan A, Gafni A, Sanders K, Mirsky D, Chambers S, O'Brien MA, Reid S, Dubois S: Effect of a decision aid on knowledge and treatment decision making for breast cancer surgery: a randomized trial. JAMA 2004, 292(4):435-441.

25. Whelan T, Sawka C, Levine M, Gafni A, Reyno L, Willan A, Julian J, Dent S, Abu-Zahra H, Chouinard E, Tozer R, Pritchard K, Bodendorfer I: Helping patients make informed choices: a randomized trial of a decision aid for adjuvant chemotherapy in lymph node-negative breast cancer. J Natl Cancer Inst 2003, 95(8):581-587.

26. O'Connor AM, Bennett CL, Stacey D, Barry M, Col NF, Eden KB, Entwistle VA, Fiset V, Holmes-Rovner M, Khangura S, Llewellyn-Thomas H, Rovner D: Decision aids for people facing health treatment or screening decisions. Cochrane Database Syst Rev 2009, CD001431, (3)(3).

27. Dorr LD, Glousman R, Hoy AL, Vanis R, Chandler R: Treatment of femoral neck fractures with total hip replacement versus cemented and noncemented hemiarthroplasty. J Arthroplasty 1986, 1(1):21-28.

28. Baker RP, Squires B, Gargan MF, Bannister GC: Total hip arthroplasty and hemiarthroplasty in mobile, independent patients with a displaced intracapsular fracture of the femoral neck. A randomized, controlled trial. J Bone Joint Surg Am 2006, 88(12):2583-2589.

29. Alolabi B, Shiali J, Bajammal SS, Karanicolas PJ, Zlowodzki M, Gafni A, Bhandari M: Preferences for the treatment of displaced femoral neck fractures: internal fixation versus hemiarthroplasty.

30. Swiontkowski MF: In Skeletal Trauma: Basic Science, Management and Reconstruction.. 3 edition. Edited by: Browner BD, Jupiter JB, Levine AM, Trafton PG. Philadelphia: Elsevier science (USA); 2003:1714-1775. 
31. Whelan TJ, Levine MN, Gafni A, Lukka H, Mohide EA, Patel M, Streiner DL: Breast irradiation postlumpectomy: development and evaluation of a decision instrument. J Clin Oncol 1995, 13(4):847-853.

32. Stacey D, Hawker G, Dervin G, Tomek I, Chochran N, Tugwell P, O'Connor PM: Management of chronic pain: improving shared decision making in osteoarthritis. BMJ 2008, 336:954-955.

33. Kelsey JL, Hoffman S: Risk factors for hip fracture. N Engl J Med 1987, 316(7):404-406.

34. Cummings SR, Nevitt MC, Browner WS, Stone K, Fox KM, Ensrud KE, Cauley J, Black D, Vogt TM: Risk factors for hip fracture in white women. Study of osteoporotic fractures research group. N Engl J Med 1995, 332(12):767-773.

35. Unnanuntana A, Gladnick BP, Donnelly E, Lane JM: The assessment of fracture risk. J Bone Joint Surg Am 2010, 92(3):743-753.

36. Greenspan SL, Myers ER, Maitland LA, Resnick NM, Hayes WC: Fall severity and bone mineral density as risk factors for hip fracture in ambulatory elderly. JAMA 1994, 271(2):128-133.

37. Greenspan SL, Myers ER, Kiel DP, Parker RA, Hayes WC, Resnick NM: Fall direction, bone mineral density, and function: risk factors for hip fracture in frail nursing home elderly. Am J Med 1998, 104(6):539-545.

38. Siminoski K, Leslie WD, Frame H, Hodsman A, Josse RG, Khan A, Lentle BC, Levesque J, Lyons DJ, Tarulli G, Brown GP: 2005 recommendations for bone mineral density reporting in Canada. Can Assoc Radiol J 2005, 56:178-188,

39. Devereaux PJ, Anderson DR, Gardner MJ, Putnam W, Flowerdew GJ, Brownell BF, Nagpal S, Cox JL: Differences between perspectives of physicians and patients on anticoagulation in patients with atrial fibrillation: observational study. BMJ 2001, 323(7323):1218-1222.

40. Slevin ML, Stubbs L, Plant HJ, Wilson P, Gregory WM, Armes PJ, Downer SM: Attitudes to chemotherapy: comparing views of patients with cancer with those of doctors, nurses, and general public. BMJ 1990, 300(6737):1458-1460.

41. Greenfield S, Kaplan S, Ware Jr: Expanding patient involvement in care. Effects on patient outcomes. Ann Intern Med 1985, 102(4):520-528.

42. Greenfield S, Kaplan SH, Ware Jr, Yano EM, Frank HJ: Patients' participation in medical care: effects on blood sugar control and quality of life in diabetes. J Gen Intern Med 1988, 3(5):448-457.

43. Hedbeck CJ, Enocson A, Lapidus G, Blomfeldt R, Törnkvist H, Ponzer S, Tidermark J: Comparison of bipolar hemiarthroplasty with total hip arthroplasty for displaced femoral neck fractures: a concise four-year follow-up of a randomized trial. J Bone Joint Surg Am 2011, 93(5):445-450.

44. Parker MJ, Gurusamy KS, Azegami S: Arthroplasties (with and without bone cement) for proximal femoral fractures in adults. Cochrane Database Syst Rev 2010, , 6: CD001706.

45. Van Den Bekerom MPJ, Hilverdink EF, Sierevelt IN, Reuling EMBP, Schnater JM, Bonke H, Goslings JC, et al: A comparison of hemiarthroplasty with total hip replacement for displaced intracapsular fracture of the femoral neck: a randomised controlled multicentre trial in patients aged 70 years and over. J Bone Joint Surg Br 2010, 92(10):422-1428

\section{Pre-publication history}

The pre-publication history for this paper can be accessed here: http://www.biomedcentral.com/1471-2474/12/289/prepub

\section{Submit your next manuscript to BioMed Central and take full advantage of:}

- Convenient online submission

- Thorough peer review

- No space constraints or color figure charges

- Immediate publication on acceptance

- Inclusion in PubMed, CAS, Scopus and Google Scholar

- Research which is freely available for redistribution

Submit your manuscript at www.biomedcentral.com/submit
Biomed Central 